\title{
AIN 焼結体の酸素と水蒸気による酸化
}

\author{
黒光祥郎・吉田秀昭 $\cdot$ 大野進司 ${ }^{*} \cdot$ 升田裕久** ${ }^{*}$ 武部博倫 ${ }^{* *}$, 森永健次** \\ 三菱マテリアル(株)中央研究所, 330 埼玉県大宮市北袋町 1-297 \\ *(株)三菱総合研究所, 100 東京都千代田区大手町 2-3-6 \\ **九州大学大学院総合理工学研究科材料開発工学専攻, 816 春日市春日公園 6-1
}

\section{Oxidation of Sintered Aluminum Nitride by Oxygen and Water Vapor \\ Yoshirou KUROMITSU, Hideaki YOSHIDA, Shinji OHNO*, Hirohisa MASUDA**, Hiromichi TAKEBE** and Kenji MORINAGA** \\ Mitsubishi Materials Corporation, Central Research Institute, 1-297, Kitabukuro-cho, Omiya-shi, Saitama \\ *Mitsubishi Research Institute, Inc., 2-3-6, Ohte-machi, Chiyoda-ku, Tokyo 100 \\ **Department of Materials Science and Technology, Graduate School of Engineering Sciences, Kyushu University, \\ 6-1, Kasugakouen, Kasuga-shi, Fukuoka 816}

[Received August 12, 1991; Accepted September 19, 1991]

Oxidation behavior of sintered AlN by oxygen and water vapor was studied at $1400^{\circ} \mathrm{C}$ for the purpose of surface treatment. The partial pressure of oxygen, $\boldsymbol{P}_{\mathbf{O}_{2}}$ was controlled at $10^{-10}$ and $10 \mathrm{kPa}$, and that of water vapor, $P_{\mathrm{H}_{2} \mathrm{O}}$ was changed at $5.0 \times 10^{-2}$ to $8.5 \mathrm{kPa}$. The oxidation product detected by XRD was $\alpha-\mathrm{Al}_{2} \mathrm{O}_{3}$. Oxidation rate was increased with increasing $P_{\mathrm{H}_{2} 0}$. The weight gain with time by oxygen was parabolic, and that by water vapor was linear. The $\mathrm{Al}_{2} \mathrm{O}_{3}$ layer formed by the oxidation of sintered AIN with oxygen was relatively dense, and coherent. The oxidation kinetics were discussed using the mixed-control rate equation on the basis of unreacted-core model.

Key-words : AlN, Oxidation, $\mathrm{Al}_{2} \mathrm{O}_{3}$, Oxygen, Water vapor, Surface treatment, Kinetics

\section{1. 緒言}

AlN セラミックスは優れた熱的, 電気的及び機械的特 性を持ち，常庄焼結による製造が可能であることから， $\mathrm{Al}_{2} \mathrm{O}_{3}$ に代わる新しい半導体実装用基板材料として注目さ れている(1) 3). しかし， AlN セラミックスを基板材料と して使用する場合には，メタライズ導体材料や厚膜ぺース ト中のガラス融体 $\left.{ }^{4}\right)$ との接着力が弱いことが深刻な問題と なっている．この対策として， AlN 基板上に高温酸化に より $\mathrm{Al}_{2} \mathrm{O}_{3}$ 層を形成し, 接着強度を高めることが検討さ れている(3) 5). AlN の酸化についてはこれまでにいくつ かの報告がなされているが6) 8), 酸素, 水蒸気などのガ 又雰囲気の影響を調べた例は少ない6).

本研究では酸素及び水蒸気による $\mathrm{AlN}$ セラミックスの 酸化挙動を調べ, 高熱伝導性 $\mathrm{A} 1 \mathrm{~N}$ 基板の表面処理のため に緻密で, $\mathrm{AlN}$ 層と密着性の良い $\mathrm{Al}_{2} \mathrm{O}_{3}$ 層の形成条件を 確立した。

\section{2. 実験方法}

試料は $12 \times 12 \times 0.65 \mathrm{~mm}$ の透光性 $\mathrm{AlN}$ 焼結体（シェイ パル，徳山曹達製）である.
酸化は $1400^{\circ} \mathrm{C} て ゙ ~ \mathrm{Ar}-\mathrm{O}_{2}$ 混合ガス雾囲気において行った。 図 1 に装置の概略図を示す。酸素分圧 $\left(P_{\mathrm{O}_{2}}\right)$ は市販の高 純度 $\operatorname{Ar}$ ガスを更に脱酸装置（図 1 中(1)）を通し, Ar ガ スに適量の $\mathrm{O}_{2}$ ガスを混合することで制御した. $P_{\mathrm{O}_{2}}$ の測 定はジルコニア酸素センサー（3）で行った. 水蒸気分圧 $\left(P_{\mathrm{H}_{2} \mathrm{O}}\right)$ は雲用気ガスをシリカゲルと五酸化二リンを充填 した乾燥系（2）を通すことで脱水し, 所定の温度に保持 した水中（4)）を通すことで調整した． $P_{\mathrm{H}_{2} \mathrm{O}}$ の測定には 露点計（Isuzu 1A，いすず製作所製；(5)）を用いた。表 1 に酸化処理の際の $P_{\mathrm{O}_{2}}$ 及び $P_{\mathrm{H}_{2} \mathrm{O}}$ の設定值を示す.なお,

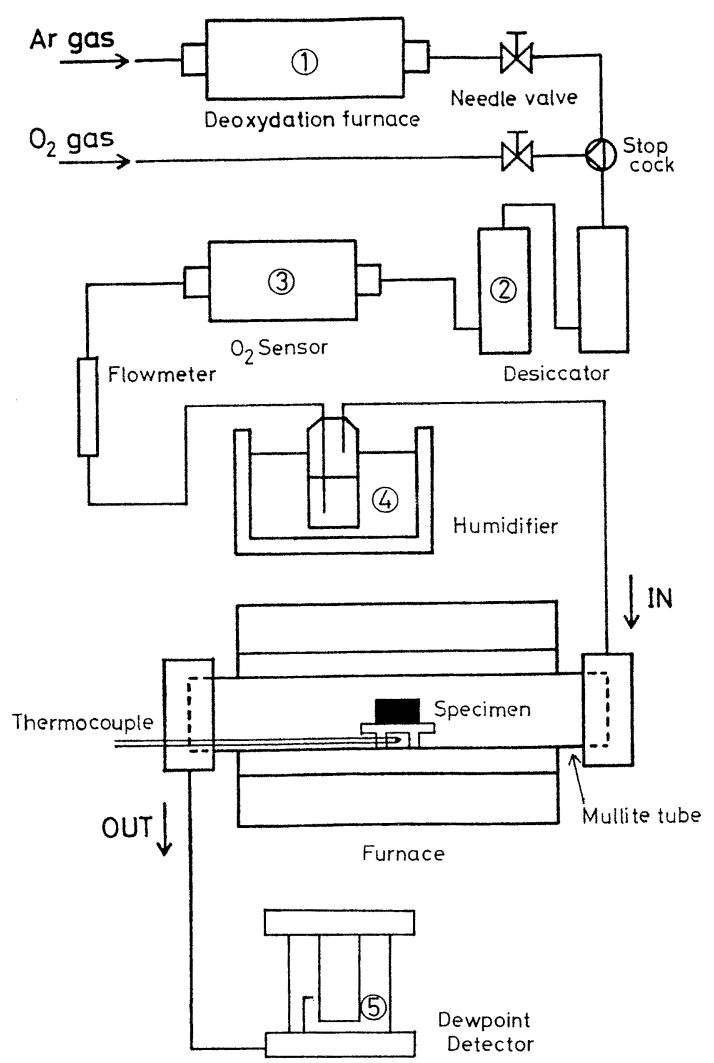

Fig. 1. Schematic diagram of oxidation apparatus. 
Table 1. Oxidation atmosphere.

\begin{tabular}{ccc}
\hline $\begin{array}{c}\text { Oxidation } \\
\text { atmosphere }\end{array}$ & ${ }^{\mathrm{P}_{2}}$ & ${ }^{\mathrm{P}_{2}{ }^{\mathrm{O}}}{ }_{(\mathrm{kPa})}$ \\
\hline Case A & $1.0 \times 10^{-10}$ & $5.0 \times 10^{-2}$ \\
Case B & $1.0 \times 10^{-10}$ & $8.6 \times 10^{-1}$ \\
Case C & $1.0 \times 10^{-10}$ & 3.1 \\
Case D & $1.0 \times 10^{-10}$ & 8.5 \\
Case E & 10 & $5.0 \times 10^{-2}$ \\
Case F & 10 & $8.6 \times 10^{-1}$ \\
Case G & 10 & 3.1 \\
Case H & 10 & 8.5 \\
\hline
\end{tabular}

酸化の際に発生する $\mathrm{NO}_{x}$ 系のガスを $\mathrm{NO}_{x}$ 自動計測器 （ECL-77A，柳本製作所製）により確認した.

酸化処理は，ムライト製の台上の AIN 試料を炉の端部 から中央の均熱部へ移動させ, 所定の時間保持した後, 速 やかに取り出すことで行った. 酸化による生成物は X 線 回折で同定した. 酸化に伴う試料の重量変化を求め, 走査 型電子顕微鏡（SEM; S-510型，日立製作所製）を用いて 試料の表面及び破面を観察した。

\section{3. 結 果}

\section{1 重量変化}

$1400^{\circ} \mathrm{C}$ で, 表 1 に示した 8 種類の雱囲気において AlN 基板を酸化させた際の生成物は，X 線回折によれば $\alpha-\mathrm{Al}_{2}$ $\mathrm{O}_{3}$ のみであった. しかし, 肉眼で酸化層の形態を観察し た結果，高酸素分圧，低水蒸気分圧の Case E, F t除く六 つの条件下で酸化させた試料においては，酸化層内の亀裂 やAlN 層との界面での剝離が認められ, 酸素と水蒸気で は AlN の酸化機構が異なることが示唆された.

予備実験としてガス流量を200〜800 ml/min の範囲で 変化させた結果，ガス流量はいずれの熱処理条件において も重量変化には影響しなかった．以下はガス流量を600 $\mathrm{ml} / \mathrm{min}$ としたときの結果のみを示す.

図 2 に重量増加と酸化時間の関係を示す． $P_{\mathrm{O}_{2}}$ が一定の 場合には，その傾きは $P_{\mathrm{H}_{2} \mathrm{O}}$ が高いほど大きい. Case E と F では, 重量増加は放物線則に従っている. そのほかの条 件下では，重量は酸化時間とともに直線的に増加してい る。すなわち，高酸素分圧，低水蒸気分圧の雾囲気では重 量は酸化時間に伴い放物線的に増加するが，他の雾囲気で は直線的に変化した。

\section{2 酸化層の形態}

図 3 に代表的な酸化層の形態を示す. Case D のように 低酸素分圧, 高水蒸気分圧下で主に水蒸気により酸化が進 行すると考えられる場合には, $\mathrm{Al}_{2} \mathrm{O}_{3}$ 粒の個々の形状は不 明確であり, 酸化により生成した $\mathrm{Al}_{2} \mathrm{O}_{3}$ 粒が連結, 成長 したことが示唆される形態である（図 $3(\mathrm{a}$ ))。屯た，酸 化層内には多くの亀裂が存在し，多孔質層を形成している のが観察される. Case E で主に酸素により $\mathrm{AlN}$ 試料を酸
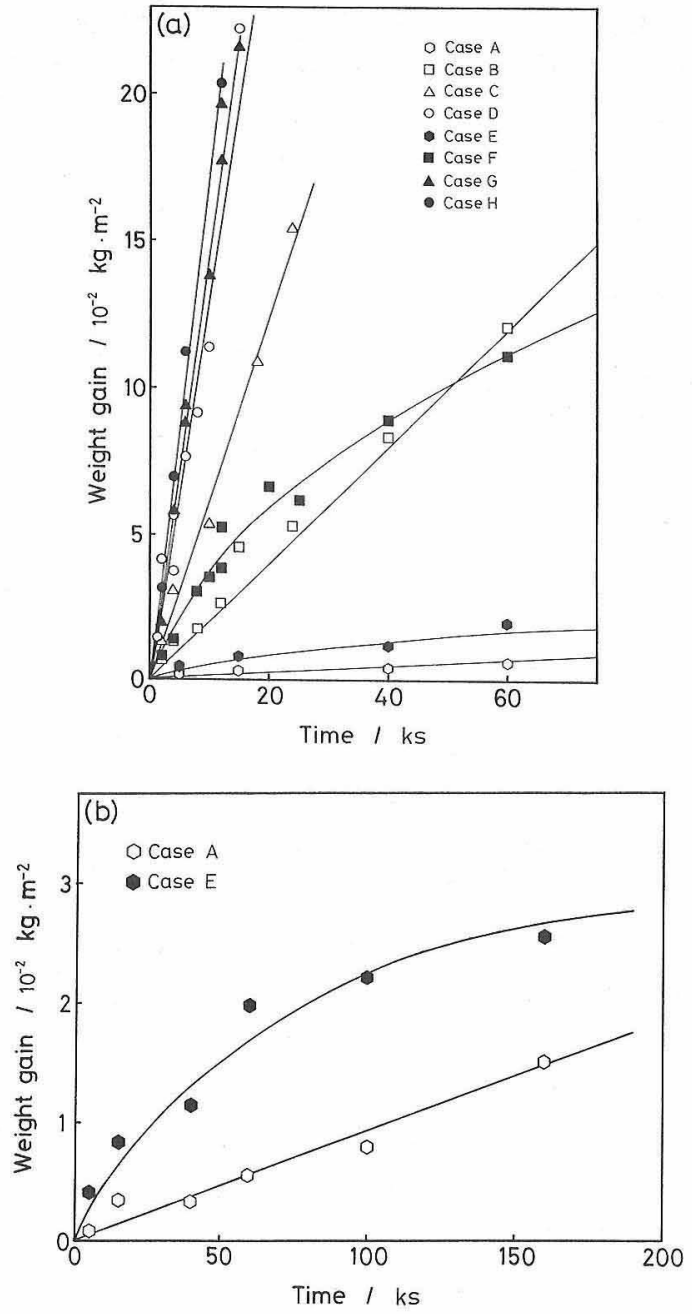

Fig. 2. Oxidation curves of a sintered AlN in (a) Cases A-H, and (b) Cases $\mathrm{A}$ and $\mathrm{E}$ for showing difference in shape of the curves.
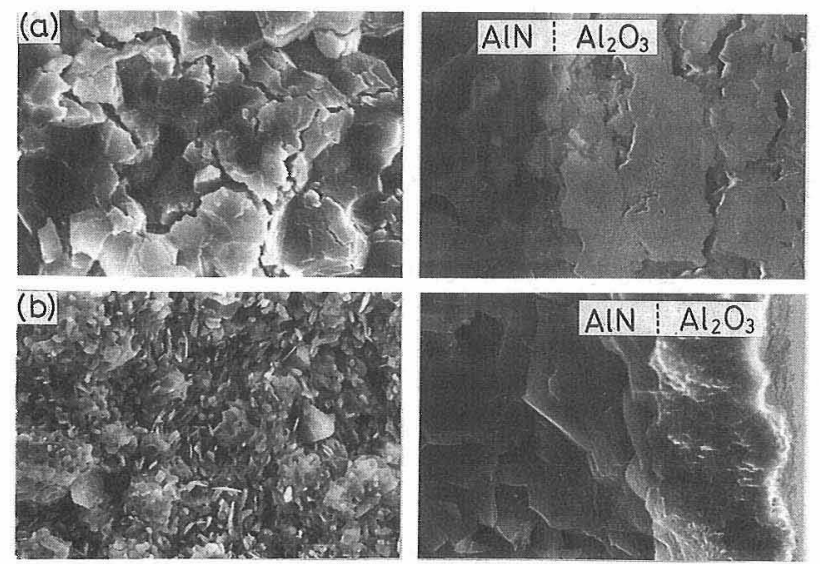

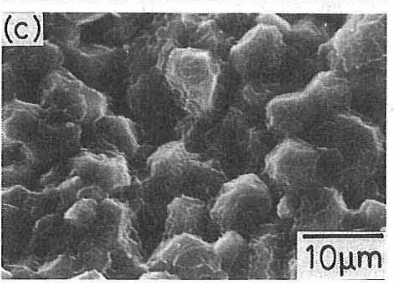

Surface

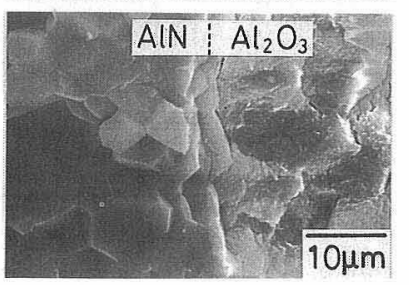

Cross section
Fig. 3. Typical morphology of surfaces and cross sections of oxidation layers in (a) Case D, (b) Case E, and (c) Case H. 
化した場合には, 酸化層は約 $3 \mu \mathrm{m} の \alpha-\mathrm{Al}_{2} \mathrm{O}_{3}$ 粒から構成 されている（図 $3(\mathrm{~b})$ ). 破面観察から，この酸化層が緻 密で AlN 層との密着性も良いことが分かる，この酸化層 は厳密には気孔が存在しないほど緻密ではないが，図 2 の結果から重量増加が放物線則に従う程度には, 比較的緻 密な層が形成されていると判断される．以下本論文ではこ の $\mathrm{Al}_{2} \mathrm{O}_{3}$ 層を緻密な酸化層と表現する. Case $\mathrm{H}$ では, 酸 素と水蒸気の両方により $\mathrm{AlN}$ 焼結体の酸化が進行するの で，酸化層は前述の二つの条件の中間的な形態を呈してい る（図 $3(\mathrm{c})$ ). なお，いずれの酸化条件においても酸化 層と未反応の $\mathrm{AlN}$ 層との界面は明瞭であり, 酸化が $\mathrm{AlN}$ 試料の表面から内部へトポケミカルに進行していることが 明らかであった。

以上の結果より, AlN 基板の表面処理のために緻密で $\mathrm{AlN}$ 層と密着性の良い酸化層を形成するには, 水蒸気分 圧を極力抑え主に酸素により $\mathrm{AlN}$ 焼結体を酸化させるこ とが必要である。

\section{3 酸化による $\mathrm{NO}_{x}$ 系ガス}

$\mathrm{AlN}$ と酸素及び水蒸気との化学反応を推定するための 一助として $\mathrm{NO}_{x}$ 系ガスの分析を行った. 図 4 に代表的な 三つの酸化条件で $\mathrm{AlN}$ 試料を酸化させた際の $\mathrm{NO}_{x}$ ガスの 分析結果を示す. 低酸素分圧, 高水蒸気分圧の Case C で は $\mathrm{NO}_{x}$ ガスの生成はほとんど認められない. 高酸素分圧, 低水蒸気分圧の Case $\mathrm{E}$ では酸化の初期にのみ微量の $\mathrm{NO}_{x}$ ガスが生成している. 高酸素分圧, 高水蒸気分圧のCase $\mathrm{G}$ では酸化時間が 300 秒むでは $\mathrm{NO}_{x}$ ガスの生成量が増大 し，それ以後は $\mathrm{NO}_{x}$ ガスが連続的に生成している.

\section{4. 考察}

\section{1 酸化反応式}

酸化による生成物が $\alpha-\mathrm{Al}_{2} \mathrm{O}_{3}$ であったことから， $1400^{\circ} \mathrm{C}$ での $\mathrm{AlN}$ と酸素及び水蒸気との反応式として (1) 〜(5) が考えられる6).

$$
\begin{aligned}
& 2 \mathrm{AlN}+7 / 2 \mathrm{O}_{2}=\mathrm{Al}_{2} \mathrm{O}_{3}+2 \mathrm{NO}_{2} \\
& \Delta G_{1400^{\circ} \mathrm{C}}^{\circ}=-597.9 \mathrm{~kJ} / \mathrm{mol} \\
& 2 \mathrm{AlN}+5 / 2 \mathrm{O}_{2}=\mathrm{Al}_{2} \mathrm{O}_{3}+2 \mathrm{NO} \\
& \Delta G_{1400^{\circ} \mathrm{C}}^{\circ}=-736.5 \mathrm{~kJ} / \mathrm{mol}
\end{aligned}
$$

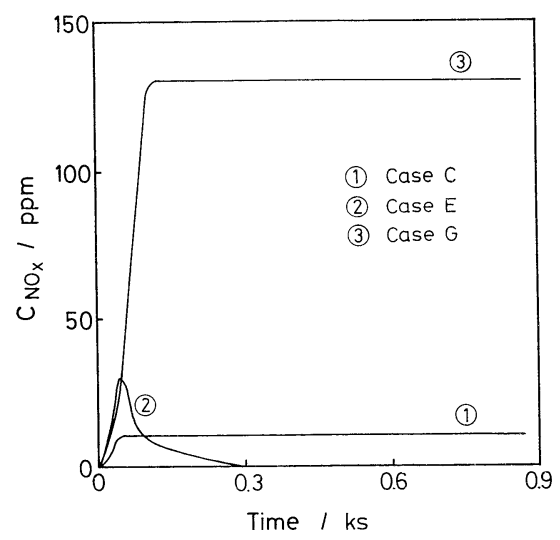

Fig. 4. $\mathrm{NO}_{x}$ gas analysis during the oxidation of a sintered AlN.

$$
\begin{aligned}
& 2 \mathrm{AlN}+3 / 2 \mathrm{O}_{2}=\mathrm{Al}_{2} \mathrm{O}_{3}+\mathrm{N}_{2} \\
& \Delta G_{1400^{\circ} \mathrm{C}}^{\circ}=-875.1 \mathrm{~kJ} / \mathrm{mol} \\
& 2 \mathrm{AlN}+3 \mathrm{H}_{2} \mathrm{O}=\mathrm{Al}_{2} \mathrm{O}_{3}+2 \mathrm{NH}_{3} \\
& \Delta G_{1400^{\circ} \mathrm{C}}^{\circ}=-128.4 \mathrm{~kJ} / \mathrm{mol} \\
& 2 \mathrm{AlN}+3 \mathrm{H}_{2} \mathrm{O}=\mathrm{Al}_{2} \mathrm{O}_{3}+\mathrm{N}_{2}+3 \mathrm{H}_{2} \\
& \Delta G_{1400^{\circ} \mathrm{C}}^{\circ}=-411.0 \mathrm{~kJ} / \mathrm{mol}
\end{aligned}
$$

$\mathrm{AlN}$ と酸素の反応が(1) 又は (2) 式に従う場合には, $\mathrm{NO}_{x}$ ガスが生成する。図 4 に示した $\mathrm{NO}_{x}$ ガスの分析結果 から, Case E で酸素においての久酸化が進行する際には, 酸化初期では酸化が(1),(2)及び(3)式に従い進行し, 緻密 な酸化膜が形成された後は熱力学に最も起こりうる，(3) の反応式に従っている. Case G で酸素と水蒸気の両方に より $\mathrm{AlN}$ の酸化が進行する条件下では, AlN と酸素との 反応式は (1),(2)及び(3)式である.

一方, Case Cのように主に水蒸気により AlN の酸化が 進行する場合には， $\mathrm{NO}_{x}$ ガスは生成しない。この $\mathrm{AlN}$ と 水蒸気の反応の初期段階に打いては, 水蒸気が $\mathrm{AlN}$ の表 面に吸着する6). 図 $3(\mathrm{a})$ に示したように, AlN と水蒸気 との反応に拐いては生成した $\mathrm{Al}_{2} \mathrm{O}_{3}$ 粒子の個々の形状が 不明瞭で, 半溶融状態を経由し生成したと推定される多孔 質の酸化層が形成されている．このような酸化層が形成さ れるのは，中間体としてベーマイト $\mathrm{A} 10 \mathrm{OH}^{9)}$ を生成する ためと考えられる。すなわち，酸化層の形態から判断する と，(6)式に示すように平衡論では起こり得ない中間体と してアルミナ水和物であるべーマイト $\mathrm{A} 10 \mathrm{OH}$ 等を極め て短い時間生成し, 連結, 合体した後, 瞬時に(7)式に従 って脱水反応が起こり熱力学的に安定な $\alpha-\mathrm{Al}_{2} \mathrm{O}_{3}$ が生成さ れるものと推定される.

$$
\begin{aligned}
& \mathrm{AlN}+2 \mathrm{H}_{2} \mathrm{O} \longrightarrow \mathrm{AlO}_{2} \mathrm{H}+\mathrm{NH}_{3} \\
& \Delta G_{1400^{\circ} \mathrm{C}}^{\circ}=+225.0 \mathrm{~kJ} / \mathrm{mol} \\
& 2 \mathrm{AlO}_{2} \mathrm{H} \longrightarrow \mathrm{Al}_{2} \mathrm{O}_{3}+\mathrm{H}_{2} \mathrm{O} \\
& \Delta G_{1400^{\circ} \mathrm{C}}^{\circ}=-578.4 \mathrm{~kJ} / \mathrm{mol}
\end{aligned}
$$

\section{2 酸化速度}

破面観察から明らかなように，A1N の酸化は表面から 内部にトポケミカルに進行していた。鉄鉱石ペレットの還

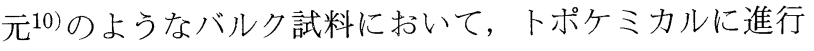
するガス-固体間反応の速度解析には, 未反応核モデルが 適用されている. AlN 焼結体の酸化反応については, 次 の過程が直列に起こる未反応核モデルを基に解析が可能で ある。

(1) AlN 焼結体の周りのガス境膜内の, 反応ガス $\left(\mathrm{O}_{2}\right.$, $\left.\mathrm{H}_{2} \mathrm{O}\right)$ の $\mathrm{AlN}$ 表面への移動（ガス境膜内拡散）

（2）生成した酸化層中の気孔を通しての反応面への酸 化ガスの移動（酸化層内桩散）

(3) 界面における化学反応 ただし，本研究では雾冊気ガスの流量が反応速度に影響し なかったことから，(1)の過程が無視できるものとして， (2)と(3)の過程を考慮し, 考察した.

図 5 は平板状の $\mathrm{AlN}$ 焼結体において, 酸化反応が試料 の両面から板厚方向（図中 $x$ 軸）のみに進行すると仮定し たときの, 未反応核モデルの図である. A $1 \mathrm{~N}$ 及び反応ガ 


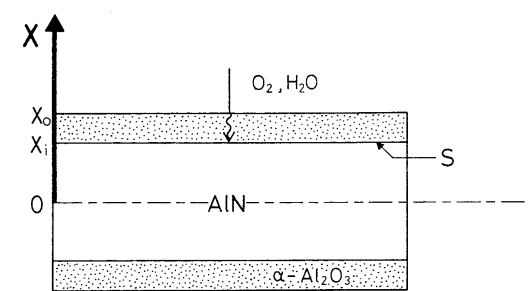

Fig. 5. Schematic diagram of unreacted-core model for a AlN plate.

スのモル反応速度をそれぞれ $\dot{n}_{\mathrm{AlN}}, \dot{n}_{\mathrm{g}}$ とし,$a$ モルの $\mathrm{AlN}$ とbモルのガスが反応するとすれば，(8)式が成立する.

$$
\frac{\dot{n}_{\mathrm{AIN}}}{a}=\frac{\dot{n}_{\mathrm{g}}}{b}
$$

時間 $\mathrm{d} t$ で $\mathrm{d} x$ の厚みの $\mathrm{AlN}$ が酸化されるとすると

$$
-\dot{n}_{\mathrm{AlN}}=2 S C_{\mathrm{AIN}} \frac{\mathrm{d} x}{\mathrm{~d} t}
$$

ここで $S$ は反応界面の面積， $C_{\mathrm{AlN}}$ は $\mathrm{AlN}$ の儿濃度であ る. 一方, 反応ガスの酸化層内拡散速度 $\dot{n}_{\mathrm{p}}$ は,

$$
-\dot{n}_{\mathrm{p}}=2 S D \frac{\mathrm{d} C}{\mathrm{~d} x}
$$

ここで $D$ は酸化層内有効拡散係数, $\mathrm{d} C$ は酸化反応に伴う ガスの濃度変化である。（10)式を $\mathrm{AlN}$ 焼結体の表面 $x_{0}$ か ら反応界面 $x_{\mathrm{i}}$ まで積分すると,

$$
-\dot{n}_{\mathrm{p}}=2 S D \frac{C_{\mathrm{g}}{ }^{0}-C_{\mathrm{g}}^{\mathrm{i}}}{x_{0}-x_{\mathrm{i}}}
$$

ここで $C_{\mathrm{g}}{ }^{0}, C_{\mathrm{g}}{ }^{\mathrm{i}}$ は，それぞれ雲囲気中及び反応界面での反 応ガス濃度である。 また, 界面での酸化反応速度 $\dot{n}_{\mathrm{c}}$ は,

$$
\dot{n}_{\mathrm{c}}=2 S k C_{\mathrm{g}}^{\mathrm{i}}
$$

ここで $k$ は化学反応速度定数である.

酸化反応が定常的に進行している場合には，- $\dot{n}_{\mathrm{g}}$ $\left(=-b / a \dot{n}_{\mathrm{AlN}}\right)=-\dot{n}_{\mathrm{p}}=\dot{n}_{\mathrm{c}}$ である. (11),(12) 式より, 測定 困難な $C_{\mathrm{g}} \mathrm{i}$ を消去して, 次式が得られる.

$$
\dot{n}_{\mathrm{c}}=\frac{2 S C_{\mathrm{g}}{ }^{0}}{\frac{x_{0} F}{D}+\frac{1}{k}}
$$

ただし，Fは(14)式で表される反応率である.

$$
F \equiv \frac{x_{0}-x_{\mathrm{i}}}{x_{0}}
$$

したがって，(8),(9),(13)式より

$$
-\frac{b}{a} 2 S C_{\mathrm{AIN}} \frac{\mathrm{d} x}{\mathrm{~d} t}=\frac{2 S C_{\mathrm{g}}{ }^{0}}{\frac{x_{0} F}{D}+\frac{1}{k}}
$$

が成立し，(14)式から $\mathrm{d} F=-\mathrm{d} x$ の関係を用いて

式を積分して整理すると，次式が得られる.

$$
\frac{a}{b} \frac{C_{\mathrm{g}}{ }^{0}}{C_{\mathrm{AIN}} x_{0}} \frac{t}{F}=\frac{x_{0}}{2 D} F+\frac{1}{k}
$$

(3),(6),(7)及び(16) 式を基に Case A E $\mathrm{A} 1 \mathrm{~N}$ の酸化速度を検討する. 低酸素分圧, 高水蒸気分王 の Case $A \sim D$ では水蒸気により, 高酸素分圧, 低水蒸気 分圧の Case E では酸素により AlN の酸化が進行する.
反応率 $F$ は，4.1節で検討したように, 酸素, 水蒸気いず れのガスとの反応に抽ても，2 モルの AlNより 1 モル の $\mathrm{Al}_{2} \mathrm{O}_{3}$ が生成することから, 重量変化を基にして次式 に従い算出した.

$$
F=\frac{2 \Delta W \cdot M_{\mathrm{AIN}}}{W\left(M_{\mathrm{Al}_{2} \mathrm{O}_{3}}-2 M_{\mathrm{AIN}}\right)}
$$

ここで, $\Delta W$ は重量変化, $W$ は酸化前の $\mathrm{AlN}$ 試料の重 量, $M_{\mathrm{AlN}}, M_{\mathrm{Al}_{2} \mathrm{O}_{3}}$ はそれぞれ $\mathrm{AlN}$ 及び $\mathrm{Al}_{2} \mathrm{O}_{3}$ の分子量であ る. (16) 式の左辺 $(a / b) \cdot\left(C_{\mathrm{g}}{ }^{0} / C_{\mathrm{AlN}} x_{0}\right) \cdot(t / F)$ と右辺の反 応率 $F$ との関係を求めると, 混合律速プロット10) と呼ば れる直線関係が得られ，グラフの傾き $x_{0} / 2 D$ から酸化層 内のガスの拡散係数 $D$ を, 切片 $1 / k$ から界面での酸化反 応速度定数 $k$ を求めることができる.

図 6 に，主に酸素により AlN の酸化が進行した場合と， 主に水蒸気により AlN の酸化が進行した場合について, 混合律速プロットを示す.酸素により $\mathrm{AlN}$ の酸化が進行 する場合の混合律速プロットは直線 1 である. 直線 1 か ら酸素による $\mathrm{AlN}$ の酸化では酸素の $\mathrm{Al}_{2} \mathrm{O}_{3}$ 層内の拡散と $\mathrm{AlN} / \mathrm{Al}_{2} \mathrm{O}_{3}$ 界面での酸化反応との二つの過程が律速（混 合律速）となることがわかる。算出される酸素の $\mathrm{Al}_{2} \mathrm{O}_{3}$ 層内の気孔内拡散係数 $D$ は $1.43 \times 10^{-5} \mathrm{~cm}^{2} / \mathrm{s}$, 反応速度 定数 $k_{\mathrm{O}_{2}}$ は $2.02 \times 10^{-2} \mathrm{~cm} / \mathrm{s}$ となる.

一方, 水蒸気により $\mathrm{AlN}$ の酸化が進行する場合の混合 律速プロットは直線 2 である. 直線 2 より水蒸気による $\mathrm{AlN}$ の酸化では, 界面での酸化反応のみが律速段階とな ることがわかる. その反応速度定数 $k_{\mathrm{H}_{2} \mathrm{O}}$ は $5.80 \times 10^{-1}$ $\mathrm{cm} / \mathrm{s}$ である. 水蒸気による反応速度定数 $k_{\mathrm{H}_{2} \mathrm{O}}$ は酸素によ る反応速度定数 $k_{\mathrm{O}_{2}}$ に比べて一けた高く, 水蒸気と酸素の 共存下での $\mathrm{A} 1 \mathrm{~N}$ の酸化速度は水蒸気との酸化反応により 支配されるものと考えられる.

以上の考察を総括すると, AlN が酸素により酸化され る場合には, 酸化速度は拡散律速に従い緻密質の酸化層が 形成されるのに対し, 水蒸気の場合には化学反応が律速で 多孔質の酸化層が形成されることが分かる. この酸化速度 についての検討を基にして, AlN の表面処理のための緻

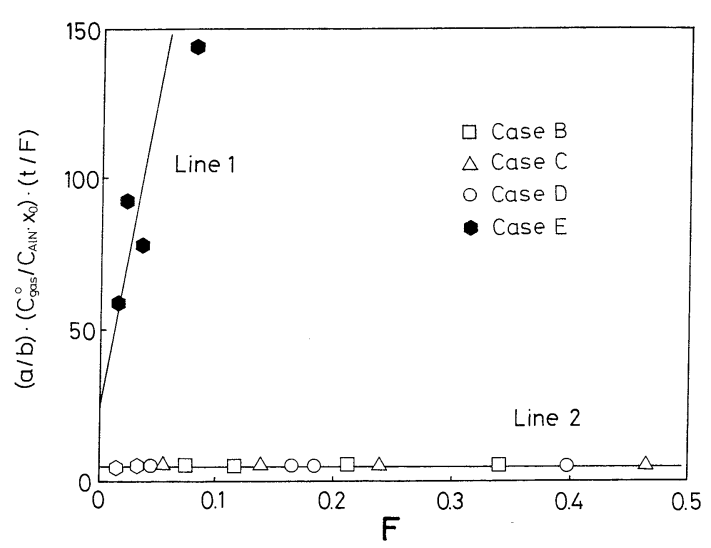

Fig. 6. Determination of effective diffusion coefficient in oxidized $\mathrm{Al}_{2} \mathrm{O}_{3}$ layer and reaction rate constant for the oxidation of a sintered AlN. 
密な $\mathrm{Al}_{2} \mathrm{O}_{3}$ 層の膜厚の制御が可能である. $\mathrm{AlN}$ と $\mathrm{Al}_{2} \mathrm{O}_{3}$ の密着性が界面での生成物, 例えば, アルミニウム酸窒化 物11)の生成に基づくものであるか否かについては今後の 検討課題である.

\section{5. 結 言}

$\mathrm{AlN}$ 焼結体の表面処理のために緻密で $\mathrm{AlN}$ 層と密着性 の良い $\mathrm{Al}_{2} \mathrm{O}_{3}$ 層の形成条件を確立することを目的として， 酸素及び水蒸気による $\mathrm{AlN}$ 焼結体の酸化挙動を調べた.

AlN 焼結体の酸化速度は水蒸気分圧により支配された。

未反応核モデルを $\mathrm{AlN}$ の酸化挙動の速度論的考察のた めに適用した。酸素による $\mathrm{AlN}$ の酸化では, $\mathrm{Al}_{2} \mathrm{O}_{3}$ 層内 のガス拡散と $\mathrm{AlN} / \mathrm{Al}_{2} \mathrm{O}_{3}$ 界面での酸化反応との二つが律 速段階である. 水蒸気による $\mathrm{AlN}$ の酸化では界面での酸 化反応のみが律速段階である.

緻密で $\mathrm{AlN}$ 層との密着性が良い $\mathrm{Al}_{2} \mathrm{O}_{3}$ 層を形成するた めには，水蒸気分圧を極力抑え主に酸素によってのみ AlN の酸化が進行する条件で熱処理を行うことが必要で ある。

酸化層の膜厚の制御は温度, 酸素分圧, 水蒸気分圧及び 時間を設定することで可能である.
謝 辞 $\mathrm{AlN}$ の酸化の速度論的考察について貴重な御助言を 下さった九州大学工学部材料工学科 · 村山武昭助教授に深く感謝 の意を表しすす。

$$
\text { 文献 }
$$

1）倉元信行, 谷口人文, 沼田吉彦, 麻生 功, 窯協, 93, 517-22 (1985)

2) Y. Kurokawa, K. Utsumi and H. Takamizawa, J. Am. Ceram. Soc., 71, 588-94 (1988).

3) N. Iwase, K. Anzai, K. Shinozaki, O. Hirao, T. D. Thanh and Y. Sugiura, IEEE Trans. Compon., Hybrids Manuf. Technol., CHMT-8, 253-58 (1985).

4) Y. Kuromitsu, H. Yoshida and K. Morinaga; Proceedings of 7th European Hybrid Microelectronics Conference, Hamburg (1989).

5) Y. Kuromitsu, T. Nagase, H. Yoshida, F. Miyazawa and Y. Ikeda, ISHM'90 Proceedings, pp. 19-26.

6) T. Sato, K. Haryu, T. Endo and M. Shimada, J. Mater. Sci., 22, 2277-80 (1987).

7) V. A. Lavrenko and A. F. Alexeev, Ceram. International, 9, 80-82 (1983).

8) H. Itoh, M. Kato and K. Sugiyama, Yogyo-Kyokai-Shi, 94, 145-50 (1986).

9) S. J. Wilson, J. Solid State Chem., 30, 247-55 (1979).

10) T. Yagi and Y. Ono, Trans. ISIJ, 8, 377-81 (1968).

11) A. D. Katnani and K. I. Papathomas, J. Vac. Sci. Technol., A5, 1335-40 (1987). 